William M. Splinter MD FRCPC, Heather V. O'Brien MD FRCPC, Lydia Komocar RN

\title{
Butorphanol: an opioid for day-care paediatric surgery
}

The purpose of this study was to compare the side effects and efficacy of equianalgesic doses of morphine $(M)$ and butorphanol $(B)$ in children undergoing similar surgical procedures associated with moderate pastoperative pain. We studied 156 healthy children aged 1.5-13 yr who underwent elective inguinal herniorrhaphy or orchidopexy. Afier induction of anaesthesia subjects were given $150 \mu \mathrm{g} \cdot \mathrm{kg}^{-1} \mathrm{M}$ or $30 \mu \mathrm{g} \cdot \mathrm{kg}^{-1}$ B following a randomized, stratified, blocked and double-blind design. $A$ standardized anaesthetic was administered, which included $1.5 \%$ halothane, vecuronium, droperidol and mechanical ventilation. The postsurgical four-hour follow-up included assessment of pain, vomiting and respiratory depression. Pain was assessed with $m C H E O P S$ and analgesics were administered when indicated in the recovery room. Each opioid was administered to a group of 78 patients. Within each group, 25 subjects had an $\dot{x}$ induction, 21 children had an orchidopexy and 57 had inguinal hernia repairs. The groups were similar with respect to age, weight, and length of surgery. The choice of opioid did not affect recovery times from anaesthesia. Analgesic requirements were similar among the groups. Ten minutes after arrival in the recovery room the B-subjects had a lower pain score than the M-patients. Pastoperative vomiting was less among the B-subjects: $14 \%$ vs $28 \%, P=0.03$. Two M-patients required an unscheduled admission to hospital because of vomiting. It is concluded that butorphanol has few advantages over morphine in the population studied.

\section{Key words}

ANAESTHESIA: paediatric;

ANALGESIA: postoperative;

ANALGESICS: butorphanol, morphine;

VOMITING: postoperative.

From the Department of Anaesthesia, Children's Hospital of Eastern Ontario and University of Ottawa, Ottawa, Ontario, Canada.

Address correspondence to: Dr. William Splinter,

Department of Anaesthesia, Children's Hospital of Eastern

Ontario, 401 Smyth Rd., Ottawa, Ontario, Canada, K1H 8L1.

This study was presented in part at the 65th Congress of the International Anesthesia Research Society, March 1991, San Antonio, Texas.

Accepted for publication 10th February, 1995.
Cette étude vise à comparer les effets secondaires et l'efficacité de doses analgésiques équivalentes de morphine (M) et de butorphanol $(B)$ chez les enfants soumis à des interventions chirurgicales de même type associées à des douleurs dintensité modérée. L'étude porte sur 156 enfants bien portants âgés de 1,5 à 13 ans soumis à une herniorraphie inguinale ou à une orchidopexie non urgentes. Après linduction de l'anesthésie, les sujets reçoivent $M, 150 \mu \mathrm{g} \cdot \mathrm{kg}^{-1}$ ou $B, 30 \mu \mathrm{g} \cdot \mathrm{kg}^{-I}$ selon la méthode des blocs répartis au hasard et à double insu. Une anesthésie standard est réalisée avec ventilation mécanique, halothane $1,5 \%$, vécuronium et dropéridol. Le suivi pastoperatoire de quatre heures comprend l'évaluation de la douleur, de lincidence des vomissements et de la dépression respiratoire. La douleur est évaluée avec mCHEOPS et les analgésiques administrés à la salle de réveil lorsque nécessaire. Chacun des morphiniques est administré à un groupe de 78 patients. A lintérieur de chaque groupe, 25 sujets reçoivent une induction intraveineuse, 21 patients subissent une orchidopexie et 57, une cure de hernie inguinale. Les groupes sëquivalent pour l'âge, le poids et la durée de la chirurgie. Le choix de l'anesthésique n'a aucune influence sur la durée de la récupération. Les besoins analgésiques sont les mêmes entre les groupes. Dix minutes après leur arrivée en salle de réveil, les sujets du groupe $B$ ont des scores de douleur inférieurs à ceux du groupe $M$ (14\% vs 28\%, $P=0,03$ ). Deux patients du groupe $M$ doivent être réadmis à l'hôpital en raison de vomissements. En conclusion, le butorphanol offre peu d'avantages sur la morphine pour la population étudiée.

An exemplary method of managing postoperative pain in children would effectively control pain for extended periods without adverse effects. Typically, postoperative pain control begins in the operating room when an anaesthetist administers opioids. ${ }^{1}$ Adverse effects, such as vomiting and respiratory depression, limit the value of this approach. ${ }^{1}$

Butorphanol (B) is an opioid analgesic with agonistantagonist effects. It has been shown to be effective in the management of postoperative pain in adults and has a half-life of $3.7 \mathrm{hr}$ and few side effects, including vomiting and respiratory depression. ${ }^{2-7}$ This opioid has minimal potential for abuse and low toxicity. ${ }^{2}$ Butorphanol has one side effect, sedation, which is ideally suited to pae- 
diatric anaesthesia. Children are often anxious in the recovery room due to parental separation and this anxiety often responds to sedation.

The aim of this study was to compare the side effects of morphine and butorphanol. We hypothesized that butorphanol, compared with equipotent doses of morphine (M) would have fewer side effects in children undergoing similar surgical procedures associated with moderate postoperative pain.

\section{Methods}

With parental consent and Hospital Ethics Committee approval 156 healthy children aged 1.5-13 yr undergoing elective repair of an inguinal hernia or undescended testicle were studied. This study followed a randomized, stratified, blocked, double-blind design. Subjects were stratified according to surgical procedure. Blocking insured equal distribution of the study drugs within strata. Children were excluded if they had a symptomatic medical illness or a history of an adverse reaction to one of the drugs to be administered during the study.

Anaesthesia was induced with halothane $/ \mathrm{N}_{2} \mathrm{O}$ by facemask or with thiopentone $5 \mathrm{mg} \cdot \mathrm{kg}^{-1} i v$ after placement of routine monitors (ECG, $\mathrm{SpO}_{2}$, non-invasive blood pressure cuff (Dinamap 1846), end-tidal halothane and end-tidal $\mathrm{CO}_{2}$ (Nellcor N-2500)). The patients were administered a standardized anaesthetic which included halothane $1.5 \%$, vecuronium $100 \mu \mathrm{g} \cdot \mathrm{kg}^{-1}$, droperidol 25 $\mu \mathrm{g} \cdot \mathrm{kg}^{-1}$, tracheal intubation and mechanical ventilation. One minute after tracheal intubation, the children were randomly given morphine $150 \mu \mathrm{g} \cdot \mathrm{kg}^{-1}$ or butorphanol $30 \mu \mathrm{g} \cdot \mathrm{kg}^{-1}$. Haemodynamic variables were measured intraoperatively every five minutes.

At the end of the operation, gastric contents were evacuated with an orogastric tube and the patients were given neostigmine $60 \mu \mathrm{g} \cdot \mathrm{kg}^{-1}$ and atropine $20 \mu \mathrm{g} \cdot \mathrm{kg}^{-1}$. Endtidal $\mathrm{CO}_{2}$ was recorded with the subject breathing halothane $1.5 \%$ spontaneously through a coaxial circuit with a fresh gas flow of $2 \mathrm{~L} \cdot \mathrm{min}^{-1}+100 \mathrm{ml} \cdot \mathrm{kg}^{-1} \cdot \min ^{-1}$. The tracheal tube was removed before airway reflexes returned.

The subjects were monitored for four hours after surgery for the following: vomiting, respiratory depression, pain and length of anaesthesia recovery. In the recovery room (PAR) respiratory rate and oxygen saturation were recorded every ten minutes. Oxygen was administered for the first ten minutes and if $\mathrm{SpO}_{2}$ was $<90 \%$. Pain was rated every ten minutes by a nurse (L.K.) using the mCHEOPS scale. ${ }^{8} \mathrm{~A}$ pain score of $\geq 6$ was treated with morphine $50 \mu \mathrm{g} \cdot \mathrm{kg}^{-1} \dot{i}$. Pain in the day-care surgical unit (DCSU) was evaluated without a scoring system by staff nurses and was treated with codeine $1 \mathrm{mg} \cdot \mathrm{kg}^{-1} \mathrm{po} / \mathrm{pr}$ or acetaminophen $10 \mathrm{mg} \cdot \mathrm{kg}^{-1}$.
TABLE I Patient characteristics

\begin{tabular}{lllll}
\hline Group & $n$ & $\begin{array}{l}\text { Age } \\
(y r)\end{array}$ & $\begin{array}{l}\text { Weight } \\
(\mathrm{kg})\end{array}$ & $\begin{array}{l}\text { Length of surgery } \\
(\text { min) }\end{array}$ \\
\hline Butorphanol & 78 & $5.5+3.0$ & $21 \pm 10$ & $46 \pm 13$ \\
Morphine & 78 & $5.1 \pm 2.6$ & $20 \pm 9$ & $45 \pm 15$ \\
\hline
\end{tabular}

Mean \pm SD.

The Aldrete recovery score was assessed every ten minutes by PAR nursing staff. ${ }^{9}$ Vomiting was recorded by nursing staff in the PAR and DCSU. Vomiting $\geq 3$ was treated with dimenhydrate $1 \mathrm{mg} \cdot \mathrm{kg}^{-1} \mathrm{pr} / \mathrm{im}$.

Data were analyzed using Chi-square analysis, ANOVA, ANCOVA, Fisher's Exact test, and KruskalWallis Rank Sum test. The acceptable alpha error was set at $5 \%$ and the acceptable beta error for sample size calculation was $20 \%$. The sample size was selected to detect clinically relevant differences in pain in the recovery room (10\% difference in analgesic requirements), vomiting (10\% difference in vomiting), and respiratory depression (4\% difference in end-tidal $\mathrm{CO}_{2}$ ).

\section{Results}

Butorphanol was administered to 78 patients. Twentyfive children in each group had $\dot{\nu}$ induction of anaesthesia. Twenty-one patients in each group had an orchidopexy and 57 subjects in each group had inguinal hernia repair.

There was no difference between the groups with respect to age, weight or duration of surgery (Table I). Intraoperative systolic blood pressure and HR were similar, except that HR at the time of incision and five minutes later was lower in the B-group (Figure).

The end-tidal $\mathrm{CO}_{2}$ was similar among the study groups at the end of the operation (Table II). Of note, an $i v$ induction was associated with a higher end-tidal $\mathrm{CO}_{2}$ than was an inhalational induction, $55 \pm 11$ vs $51 \pm 10$, mmHg, mean $\pm \mathrm{SD}, P=0.03$, ANOVA. The $\mathrm{SpO}_{2}$ was not different in the PAR among the study groups. No patient required supplemental $\mathrm{O}_{2}$ beyond ten minutes after arrival in the PAR.

The choice of opioid did not alter recovery times from anaesthesia. The B-subjects and M-subjects had Aldrete recovery scores of 10 at $50 \pm 16$ and $45 \pm 18 \mathrm{~min}$, mean $\pm S D$, respectively.

Thirty B-patients and $40 \mathrm{M}$-patients did not require an analgesic (codeine and/or morphine and/or acetaminophen) in the four hours after anaesthesia. Ten minutes after arrival in the PAR the B-subjects and the subjects who had a hernia repair had a lower pain score (Table III).

Butorphanol patients had a reduced incidence of post- 

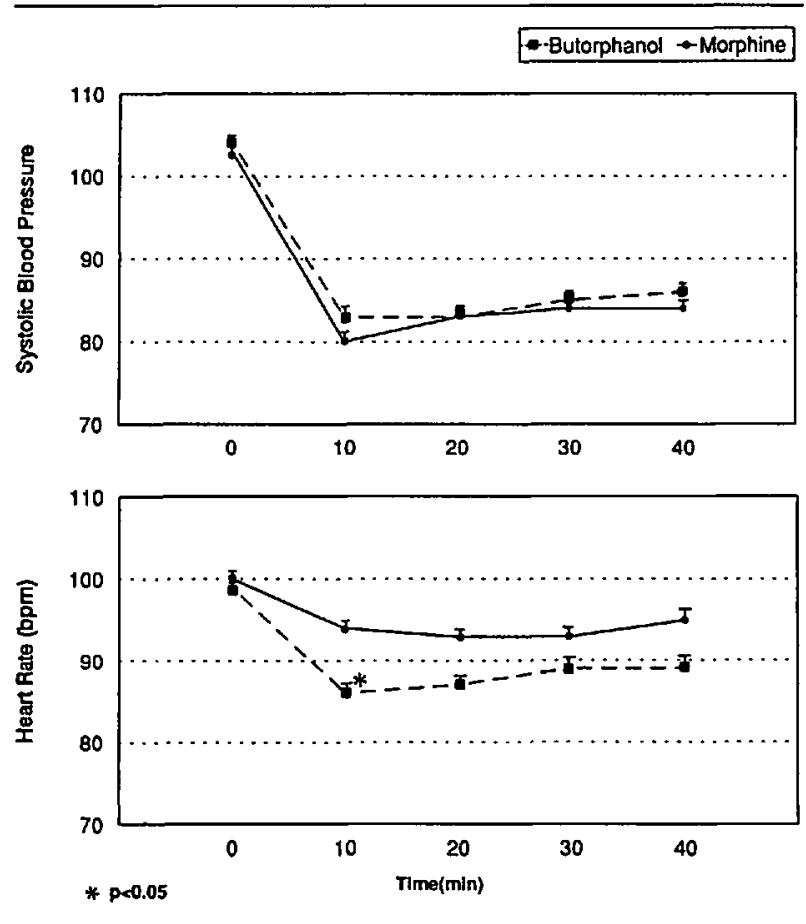

FIGURE Heart rate and systolic blood pressure for both groups at time 0 ( 30 seconds after incision) and at multiples of $10 \mathrm{~min}$ after this initial assessment.

operative vomiting, $14 \%$ (B) vs $28 \%$ (M), $P=0.03$, Chisquare analysis. Hernia repair was associated with a higher incidence of vomiting, 25\%, than orchidopexy, $10 \%, P=0.03$, Chi-square analysis. Protracted postoperative emesis by two patients in the M-Group led to unscheduled admission to hospital after surgery.

\section{Discussion}

Butorphanol is not an ideal opioid, but it has some advantages over morphine in the population studied.

The dose of morphine in this study was chosen to be effective, but with minimal adverse reactions. The chosen butorphanol dose was to be equianalgesic but the difference in pain scores and morphine use in the PAR imply that the doses were not equianalgesic. There is an al-
TABLE II Respiratory depression

\begin{tabular}{llll}
\hline Group & $\begin{array}{l}\text { End-tidal } \\
\mathrm{CO}_{2}(\mathrm{mmHg})\end{array}$ & $\begin{array}{l}\text { Average PAR } \\
\text { resp. rate }(\mathrm{bpm})\end{array}$ & $\begin{array}{l}\text { Average PAR } \\
\mathrm{O}_{2} \text { saturation }\end{array}$ \\
\hline Butorphanol & $53 \pm 11$ & $23 \pm 4$ & $99 \%$ \\
Morphine & $51 \pm 11$ & $22 \pm 4$ & $98 \%$ \\
\hline
\end{tabular}

Mean \pm SD.

ternative explanation of this difference in pain scores. The behaviour based pain scale used in this study may be affected by the different psychopharmacologic effect of butorphanol. ${ }^{10}$ That is, butorphanol's sedative effect may have been associated with decreased pain scores.

The B-subjects had a 50\% lower incidence in vomiting than the morphine-treated patients. This is in agreement with Caruso et al. ${ }^{11}$ The overall observed incidence of postoperative vomiting is comparable to the published rates of $20-70 \%$ after similar paediatric surgery/anaesthesia. ${ }^{12,13}$ The aetiology of the decreased emesis is unknown.

Butorphanol produces a finite respiratory depression. With the morphine and butorphanol doses used in this study we were unable to detect a difference in respiratory depression. This is consistent with Rosow who stated that similar respiratory depression occurred in adults who had received $10 \mathrm{mg}$ morphine or $2 \mathrm{mg}$ butorphanol after surgery. ${ }^{1}$

In this study we observed a brief period of decreased heart rate at the beginning of anaesthesia, which has been noted previously during adult ambulatory anaesthesia. ${ }^{14}$ We are unaware of an explanation of this event. The detected difference appears to be of no practical significance.

The sedative effect of butorphanol has limited benefits. Although advantageous in the PAR, it should not prolong PAR and DCSU stay. In our study of $30 \mu \mathrm{g} \cdot \mathrm{kg}^{-1}$ butorphanol, we observed no change in PAR stay and DCSU stay among the B-subjects, in spite of the fact that they had less pain and decreased vomiting. In one adult study ${ }^{15}$ three patients required admission because of excess drowsiness after $60 \mu \mathrm{g} \cdot \mathrm{kg}^{-1}$ butorphanol and

TABLE III mCHEOPS score in PAR

\begin{tabular}{lrllll}
\hline \multicolumn{5}{l}{ Pain score in PAR at 10 min intervals } \\
\cline { 3 - 6 } Group & \multicolumn{1}{c}{$n$} & 10 & 20 & 30 & 40 \\
\hline Butorphanol & 78 & $2.0 \pm 0.3$ & $2.5 \pm 1.3$ & $2.9 \pm 1.9$ & $2.4 \pm 1.2$ \\
Morphine & 78 & $2.6 \pm 1.4^{*}$ & $2.7 \pm 1.6$ & $2.7 \pm 1.5$ & $2.5 \pm 1.1$ \\
Hernia & 114 & $2.2 \pm 0.9$ & $2.5 \pm 1.3$ & $2.8 \pm 1.7$ & $2.4 \pm 1.2$ \\
Orchidopexy & 42 & $2.6 \pm 1.4 \dagger$ & $3.0 \pm 1.8$ & $2.8 \pm 1.6$ & $2.3 \pm 1.1$ \\
\hline
\end{tabular}

Mean $\pm \mathrm{SD},{ }^{*} P<0.002$, B vs M; $† P<0.02$, hernia vs orchidopexy, Kruskal-Wallis Rank test. 
Pandit et al. ${ }^{16}$ recommend avoidance of high-dose butorphanol in a day-care setting. The mechanism of the sedation is unknown, but it is qualitatively indistinguishable from that of midazolam. ${ }^{17}$

This study has several potential deficiencies. Assessment of pain in the paediatric PAR is difficult. The tool used in this study, mCHEOPS, is behaviour based. It is valid and reliable, ${ }^{8}$ but a child's "pain" behaviour, such as crying, has a multifactorial aetiology, of which pain is only one component. Unfortunately, a superior tool does not exist. Another potential flaw was the brief, fourhour postanaesthetic follow-up. This may have resulted in an underreporting of adverse events, including emesis. If the follow-up had been extended, confounding factors such as opioid administration in PAR and DCSU may have influenced the results.

In summary, replacement of intraoperative morphine with butorphanol for treatment of mild to moderate postoperative paediatric pain had minimal effect on postoperative pain, decreased vomiting but without an increase in adverse events. However, the differences are small and of little clinical importance.

\section{Acknowledgements}

We would like to thank our colleagues in the Departments of Anaesthesia, Surgery and Nursing for their cooperation and support during this investigation.

\section{References}

1 Mitchell RWD, Smith G. The control of acute postoperative pain. Br J Anaesth 1989; 63: 147-58.

2 Rosow CE. Butorphanol in perspective. Acute Care 1986; 12 (suppl 1); 2-7.

3 Quilligan EJ, Keegan KA, Donahue MJ. Double-blind comparison of intravenously injected butorphanol and meperidine in parturients. Int J Gynaecol Obstet 1980; 18: 363-7.

4 Kallos T, Caruso FS. Respiratory effects of butorphanol and pethidine. Anaesthesia 1979; 34: 633-7.

5 Maduska AL. Butorphanol in obstetrical anesthesia. Anesthesiology Review 1981; 8: 14-7.

6 Ramsey $R$, Higbee $M$, Maesner $J$, Wood J. Influence of age on the pharmacokinetics of butorphanol. Acute Care 1986; 12 (suppl 1): 8'-16.

7 Nagashima H, Karamanian A, Malovany $R$, et al. Respiratory and circulatory effects of intravenous butorphanol and morphine. Clin Pharmacol Ther 1976; 197: 738-45.

8 Splinter WM, Semelhago L, Chou S. The reliability and validity of a modified CHEOPS pain score. Anesth Analg 1994; 78: S413.

9 Aldrete JA, Kroulik $D$. A postanesthetic recovery score. Anesth Analg 1970; 49: 924-34.
10 Zacny JP, Lichtor JL, Thapar P, Coalson DW, Flemming $D$, Thompson $W$. Subjective and psychomotor responses to I.V. butorphanol and morphine in healthy volunteers. Anesth Analg 1994; 78: S498.

11 Caruso FS, Pircio AW, Madissoo H, Smyth RD, Pachter IJ. Butorphanol. American Pharmaceutical Sciences 1979; 2: 19-57.

12 Schindler $M$, Swann $M$, Crawford $M$. A comparison of postoperative analgesia provided by wound infiltration or caudal anaglesia. Anaesth Intensive Care 1991; 19: 46-9.

13 Cross GD, Barrett RF. Comparison of two regional techniques for postoperative analgesia in children following herniotomy and orchidopexy. Anaesthesia 1987; 42: 845-9.

14 Philip BK, Scott DA, Freiberger D, Gibbs RR, Hunt $C$, Murray $E$. Butorphanol compared with fentanyl in general anaesthesia for ambulatory laparoscopy. Can $\mathbf{J}$ Anaesth 1991; 38: 183-6.

15 Fine J, Finestone SC. A comparative study of the sideeffects of butorphanol, nalbuphine and fentanyl. Anesthesiology Review 1981; 8: 13-7.

16 Pandit SK, Kothary SP, Pandit UA, Mathai MK. Comparison of fentanyl and butorphanol for outpatient anaesthesia. Can J Anaesth 1987; 34: 130-4.

17 Dershwitz $M$, Rosow CE, DiBiase PM, Zaslavsky $A$. Comparison of the sedative effects of butorphanol and midazolam. Anesthesiology 1991; 74: 717-24. 